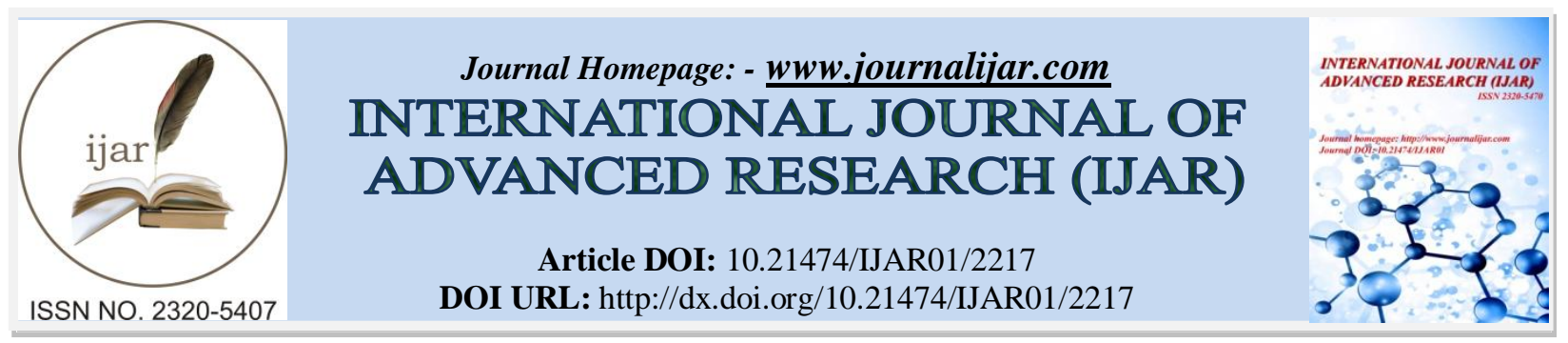

RESEARCH ARTICLE

\title{
TUNGSTATE -BASED COATING ON ZE41 MG-ZN-RARE-EARTH ALLOY.
}

\author{
Enas M. Attia ${ }^{1}$, W.A.Ghanem ${ }^{2}$ and *Hoda M. Hussien ${ }^{2}$.
}

1. Faculty of Science, Al_Azhar University, Cairo, Egypt.

2. Central Metallurgical Research and Development Institute, P.O. Box: 87, Helwan, 11421 Cairo, Egypt.

\section{Manuscript Info}

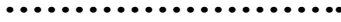

Manuscript History

Received: 28 September 2016

Final Accepted: 30 October 2016

Published: November 2016

Key words:-

Advanced materials, Tungstate, ZE41

Mg-Zn-rare earth alloy, Clean Protective

Coating and Corrosion.

\section{Abstract}

Rare-earth ZE41 alloy possesses unique mechanical properties. However, the sharp potential difference between the rare-earth phases (cathode) inside the $\mathrm{Mg}$ matrix (anode) results in building up microelectrochemic al cells and enhancing galvanic corrosion. The optimum conditions for obtaining protective tungstate coatings having improved corrosion resistance for ZE41 alloy were determined. A simple one step surface treatment in $4 \mathrm{~g} / \mathrm{l}$ tungstate coating solution for short time was found promising to improve the localized corrosion resistance.

Copy Right, IJAR, 2016,. All rights reserved.

\section{Introduction:-}

Weight reduction of automobiles is one of the most effective ways of improving fuel consumption, since the resistance of a vehicle to rolling, climbing and acceleration is directly dependent on its mass. Weight reduction in aircraft is similarly appropriate. Consequently, there is increasing research and industrial interest in the automotive and aerospace industries in replacing traditional, heavy materials with light weight materials such as magnesium and aluminum-based alloys, and multi-material solutions, with the aim of reducing fuel consumption and $\mathrm{CO}_{2}$ emissions. Magnesium alloys, with densities of only about one-quarter that of steel and two-thirds that of aluminum are, therefore, expected to find increasing application.

Although magnesium alloys have a variety of excellent properties, including a high strength-to-weight ratio, low density, dimensional stability and castability, the high corrosion susceptibility of magnesium alloys, particularly galvanic corrosion, retards their wider application in industry. Many techniques have been tried to improve the corrosion resistance of $\mathrm{Mg}$ alloys [1-2]. Examples of these techniques are: Some schemes have, indeed, been proposed, for example, changing the chemical composition of the alloys through addition of some rare-earth elements such as $\mathrm{Zr}, \mathrm{Ce}, \mathrm{Nd}$,..etc (example is the alloy under investigation in this report), surface modification treatments prior to applying the coating, or the use of protective films and coatings.

The most effective process considering the feasibility issues for possible scaling-up in industrial application is the conversion coating technique. Chemical conversion coating have been extensively used for improving the corrosion resistance of magnesium alloys [13-27]. Chromate baths containing hexavalent chromium compounds have been the most common industrial conversion coatings for steel, aluminum and magnesium alloys. Chromium conversion coating was the best ever during the last century to produce smart protective films with self-healing functionalities. However, chromate conversion coatings are now being banned due to their toxicity and carcinogenic effect.

Corresponding Author:- Hoda M. Hussien.

Address:- Faculty of Science, Al_Azhar University, Cairo, Egypt. 
Chrome-free eco-friendly conversion coatings for magnesium alloys have thus received ever-increasing attention during the last decade, including environmentally acceptable salts of zirconate, vanadate, stannate, rare-earth metal salt, phosphate, titanate, and phosphate/permanganate conversion coatings [13-27]. Despite the intensive research efforts invested to optimize a chrome-free coating technology on magnesium alloys, the problem of replacement toxic chromate has not been resolved yet and, it is unfortunate that the toxic chromate are still used in the industry.

Sabouri, et al. [3] compared between polypyrrole (PPy) and polypyrrole-tungstate ( $\left.\mathrm{PPy}-\mathrm{WO}_{4}-2\right)$ coatings electropolymerized on carbon steel using oxalic acid solutions containing pyrrole and pyrrole-tungstate, The electropolymerizations have carried out using cyclic voltammetry at the scan rate of $20 \mathrm{mVs}^{-1}$. Electrochemical impedance spectroscopy (EIS) has also used to evaluate the performance of coatings on carbon steel surfaces under immersion in a 3.5\% sodium chloride $(\mathrm{NaCl})$ solution. Obtained results revealed that PPy-WO4-2 coating provided a noticeable protection enhancement against corrosion progression.

Ding, et al. [4] studied the effect of Oxide coatings on AM60B magnesium alloy prepared using the microarc oxidation (MAO) technique in silicate- $\mathrm{KOH}$ electrolyte with addition of $0-6.0 \mathrm{~g} / \mathrm{L} \mathrm{Na} \mathrm{WO}_{4}$. The MAO processes in base electrolyte with different concentrations of $\mathrm{Na}_{2} \mathrm{WO}_{4}$ have been studied. It is found that the addition of $\mathrm{Na}_{2} \mathrm{WO}_{4}$ into the base electrolyte has direct effect on the characteristics of voltage-time curves and breakdown voltage in MAO process. The number of micropores at top of the coating surface was increased by the addition of $\mathrm{Na}_{2} \mathrm{WO}_{4}$. The fraction of forsterite $\mathrm{Mg}_{2} \mathrm{SiO}_{4}$ in the oxide coating increases with increasing concentration of $\mathrm{Na}_{2} \mathrm{WO}_{4}$ in base electrolytes.

Chun-Chieh, et al. [5], investigated the effects of sodium tungstate concentrations and current density on the surface morphology, phase composition and properties for microarc oxidation (MAO) coatings on 5020 aluminum alloy which prepared in silicate- hypophosphite electrolytes with sodium tungstate. The results also show that the MAO coatings are composed mainly of $\alpha-\mathrm{Al}_{2} \mathrm{O}_{3}$ and $\gamma-\mathrm{Al}_{2} \mathrm{O}_{3}$ and the proportion of $\alpha-\mathrm{Al}_{2} \mathrm{O}_{3}$ and $\gamma-\mathrm{Al}_{2} \mathrm{O}_{3}$, pore size, surface roughness as well as thickness of the coatings strongly depend on the sodium tungstate concentration and current density.

Kamaraj, et al. [6] investigated the corrosion protection performance of tungstate doped polyaniline containing vinyl coating on steel. The tungstate doped polyaniline was chemically synthesized and characterized by FTIR, XRD, UV-VIS and TGA studies. The corrosion protection performance of vinyl coating containing tungstate doped polyaniline on steel was assessed in $3 \% \mathrm{NaCl}$ by electrochem.ical impedance studies (EIS).The coating has been found to offer protection more than 60 days in salt spray and immersion in 3\% NaCl.FTIR studies have shown that the formation of iron-tungstate complex along with the passive film on steel.

In another study, Xin Shu, et al. [7] successfully designed a new ternary Ni-W-P coatings electrolessly plated on an $\mathrm{Al}$ alloy substrate. The results indicated that by controlling the bath composition and process parameters, the percentage of Wand $\mathrm{P}$ in the coating could be optimized while using a constant amount of sodium tungstate. The presence of stabilizers in the bath had a significant influence on the Wand P content of the coatings.

The present paper aims to explore a new tungstate surface treatment approach on ZE41 magnesium alloy. The optimum conditions under which tungstate based coatings can provide good corrosion protection for ZE41 magnesium alloy substrate will be determined. The simplicity and safety of the coating process gives it its importance as an outstanding coating method for magnesium alloys.

\section{Experimental:-}

\section{Materials and surface preparation:-}

Specimens of Mg-Zn-rare earth alloy Elektron ${ }^{\circledR}$ RZ5 (Elektron ZE41 also given the code DF 9690) in the form $30 \mathrm{x}$ $60 \times 3 \mathrm{~mm}$ were cut from a sand cast plate $100 \times 200 \times 25 \mathrm{~mm}$ provided by Magnesium Elektron, UK. The specimens were abraded to 800 \# finish with $\mathrm{SiC}$ grit papers, degreased in acetone, washed with distilled water, and dried in air. The alloy chemical composition, as provided by the supplier [1], is Zinc 3.5-5.0\%, Rare Earths 0.8$1.7 \%$, Zirconium $0.4-1.0 \%$, and Magnesium balance.

\section{Solutions and surface treatment:-}

The coatings are deposited from aqueous solutions containing sodium tungstate using a very simple spontaneous free immersion processing technology that is very similar to that currently used for the toxic chromate system. A 
thin layer of manganese oxide conversion coatings is deposited on the magnesium alloy surface by a chemically driven deposition process. Depositions are achieved in 10 minutes and use commercially available chemical, materials and equipment, making the overall process compatible with industrial operations such as those employed by current aircraft manufacturers.

Solutions used in this work were prepared using sodium tungstate salt with different tungstate solution concentrations. The newly developed ZE41 magnesium alloy substrates were treated directly by simple free immersion for 10 minutes in tungstate solutions having different concentrations namely; $0,2,4,7,10,15$ and $20 \mathrm{~g} / \mathrm{l}$ $\mathrm{WO}_{4}$ at neutral $\mathrm{pH}$ and at room temperature while the solution was open to air. As-polished samples (uncoated) were used as a blank.

\section{Electrochemical Testing:-}

Electrochemical Impedance Spectroscopy (EIS):-

EIS technique was used to evaluate the electrochemical behavior of the uncoated (as-polished) and coated samples in $3.5 \% \mathrm{NaCl}$ solution open to air and at room temperature for up to seven days. A three-electrode set-up was used with impedance spectra being recorded at the corrosion potential $\mathrm{E}_{\text {corr }}$. A saturated calomel electrode (SCE) was used as the reference electrode. It was coupled capacitively to a Platinum wire to reduce the phase shift at high frequencies. EIS was performed between $0.01 \mathrm{~Hz}$ and $65 \mathrm{kHz}$ frequency range using a frequency response analyzer (Electrochemical analyzer instrument: Autolab PGSTAT 30). The amplitude of the sinusoidal voltage signal was 10 $\mathrm{mV}$. The exposed surface area was $2.54 \mathrm{~cm}^{2}$. All curves were normalized to $1 \mathrm{~cm}^{2}$.

\section{Cyclic voltammetry measurements:-}

Cyclic voltammetry measurements of the samples previously immersed for seven days in $3.5 \% \mathrm{NaCl}$ solution were made at a scan rate of $0.07 \mathrm{mV} / \mathrm{s}$ using Autolab PGSTAT 30. The potential was recorded starting from a cathodic potential $(-100 \mathrm{mV})$ and be allowed to sweep to anodic potential direction till a sudden shift in the current in the active direction is observed. At that point the sample will be enforced to sweep again in the cathodic direction. The exposed surface area was $2.54 \mathrm{~cm}^{2}$. All curves were normalized to $1 \mathrm{~cm}^{2}$.

\section{Surface characterization:-}

SEM and EDS were used to examine the surface morphology of the coated samples before and after the immersion in 3.5\% $\mathrm{NaCl}$ solution. SEM images were obtained for samples immersed in 3.5\% $\mathrm{NaCl}$ for seven days, washed with deionized water and then dried. Each analysis was preformed three times at different spots using screen analysis at very high magnification covering the all size of the spot.

Macroscopic images were taken using Digital Optical metallographic microscope KEYENCE, VHX-100K, KEYENCE, Japan, to investigate the types of corrosion produced on the substrate surfaces after seven days of immersion in $3.5 \% \mathrm{NaCl}$ solution.

\section{Results and Discussion:- \\ Surface Examination:- \\ Visual inspection and macro-images:-}

Visual inspection of tungstate coated samples was carried out after seven days of immersion in $3.5 \% \mathrm{NaCl}$ solution and macro-images were acquired using a digital camera (Fig. 1) revealed severe pitting corrosion for the uncoated as-abraded samples. The average number and size of pits decreased after applying tungstate coatings of diluted concentrations (namely 2 and $4 \mathrm{~g} / \mathrm{l}$ ). Increasing the tungstate concentration above $4 \mathrm{~g} / \mathrm{l}$ has, generally, an adverse effect on the protection performance of magnesium substrate to localized corrosion (pitting, crevice and microcracks). The number and the size of pits(the pitting density) increased dramatically for the samples coated with 7 and $15 \mathrm{~g} / \mathrm{l}$ tungstate. 

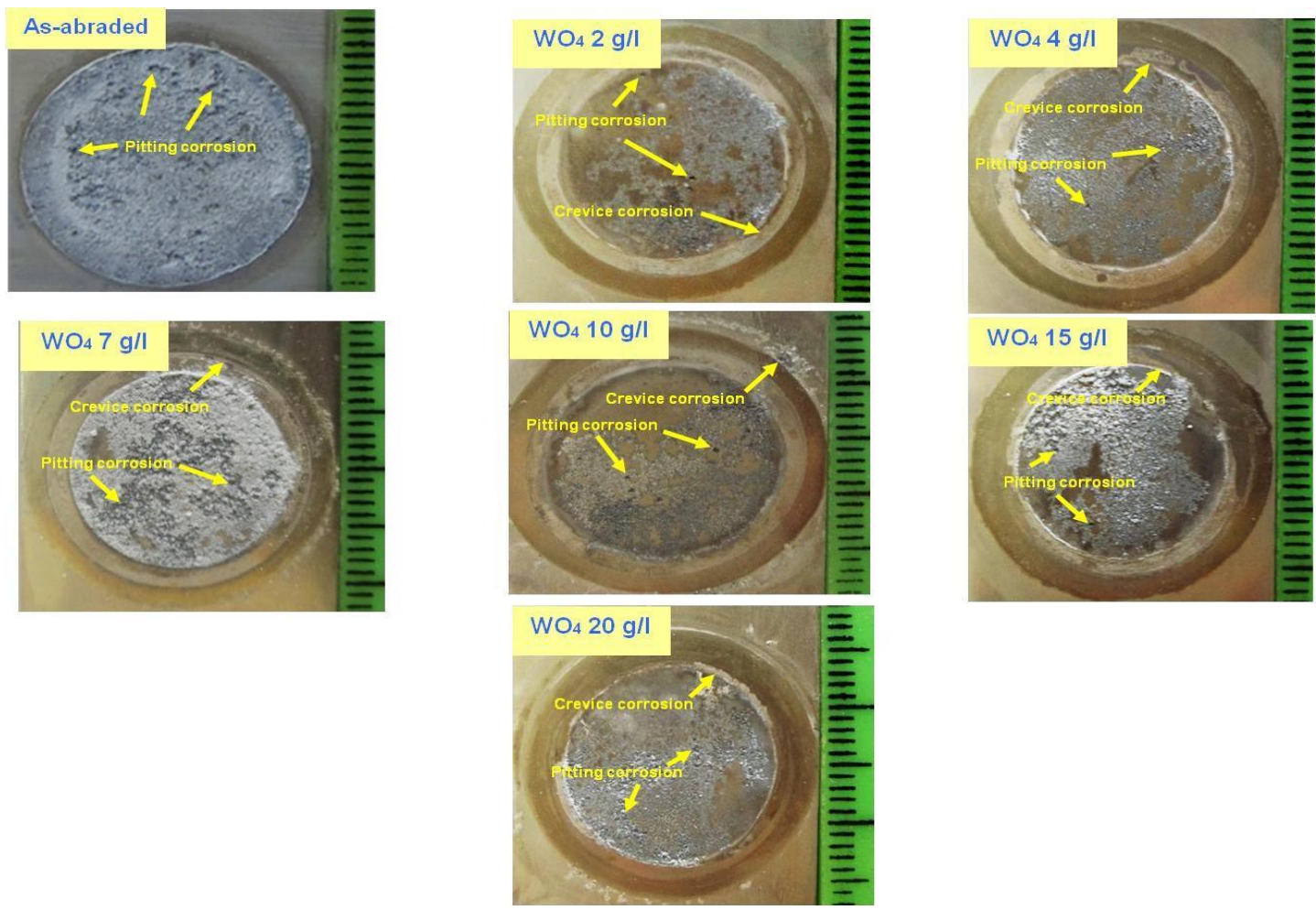

Figure 1:- Macroscopic images of tungstate coated ZE41 magnesium alloy after one week of free immersion in 3.5 $\% \mathrm{NaCl}$ solution

The number of pits was calculated to be about $8,2,1,13,2,1$ and 8 pits $/ \mathrm{cm}^{2}$ for the samples treated in $0,2,4,7,10$, 15 and $20 \mathrm{~g} / \mathrm{l}$ tungstate solution respectively (Fig. 1). Fig. 2 summarizes the pitting corrosion density of the asabraded and tungstate coated samples. Although the samples coated with 7 and $15 \mathrm{~g} / 1$ tungstate showed noticeable resistances to pitting corrosion, some micro-cracks and crevice corrosion have been observed. The sample treated in $4 \mathrm{~g} / \mathrm{l}$ tungstate solution showed the best resistance to micro-cracks, pitting, and crevice corrosion.

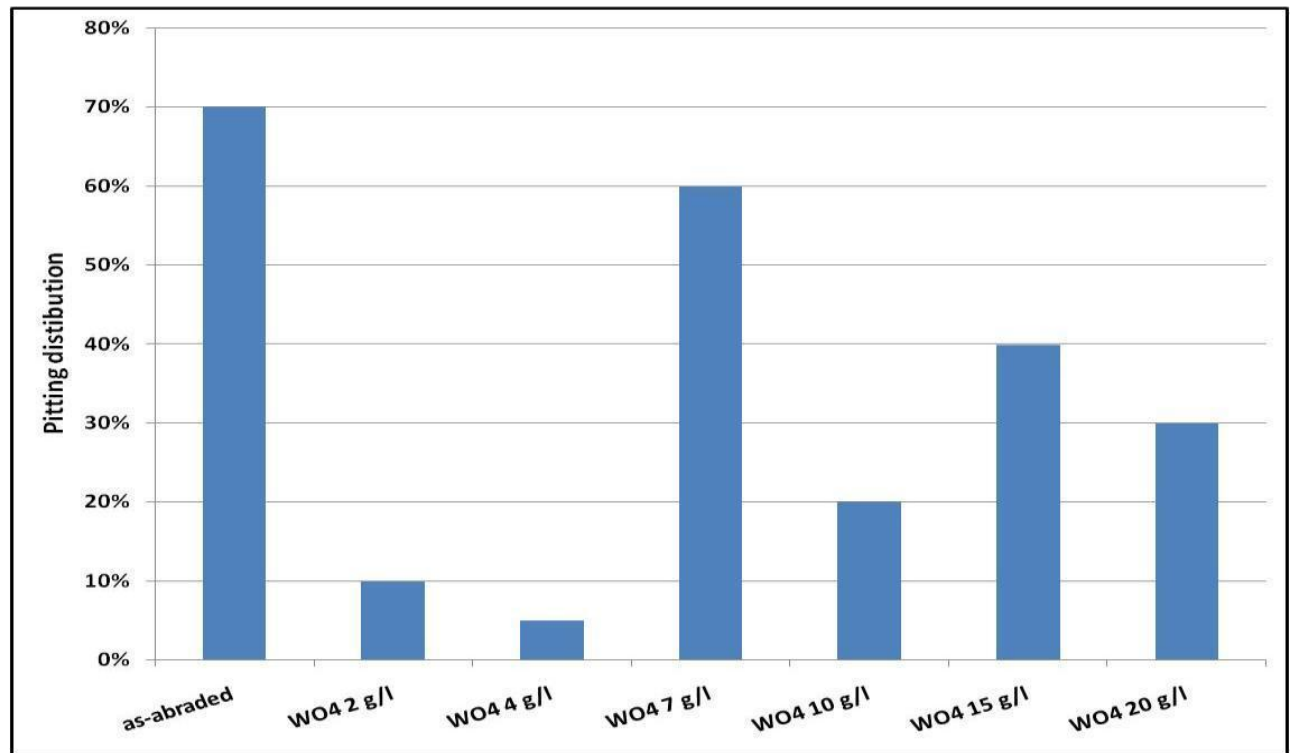

Figure 2:- Pitting corrosion density of tungstate coated composite samples after one week of immersion in $\mathrm{NaCl}$ solutions. 


\section{Optical microscopic images:-}

Optical microscopy was used to examine the pitting zones and to examine the appearance of the protective film formed at the material surface. Fig. 3 outlines the surface appearance of the as-abraded and tungstate coated samples before corrosion. Some micro cracks and other surface defects were obtained on the coated samples; e.g. micro cracks shown at $2 \mathrm{~g} / \mathrm{l}$ tungstate.
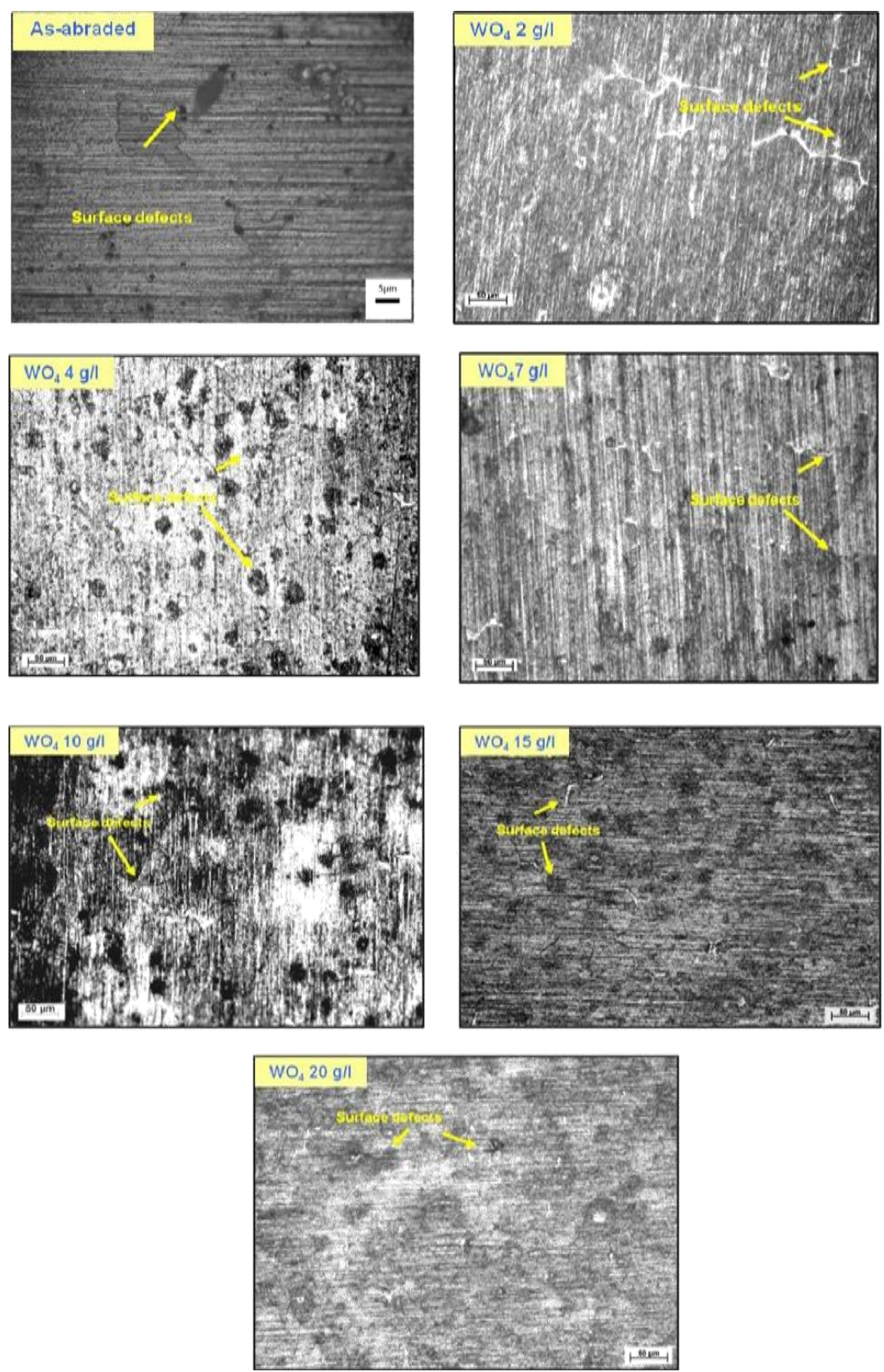

Figure 3:- Microscopic images of for the newly developed ZE41 magnesium alloy substrates coated in the presence of different tungstate concentration at 10 minutes immersion time.

Fig. 4 shows the tungstate coated samples after corrosion testing. The figure revealed that increasing the tungstate concentration from 0 to $20 \mathrm{~g} / \mathrm{l}$ resulted in improving the corrosion inhibition characteristics of the coatings. Further increase in the tungstate concentration affects negatively the protective performance of the coatings. The number of pits, their sizes and their depth were decreased in 2 or $4 \mathrm{~g} / \mathrm{l}$ tungstate coated samples. 

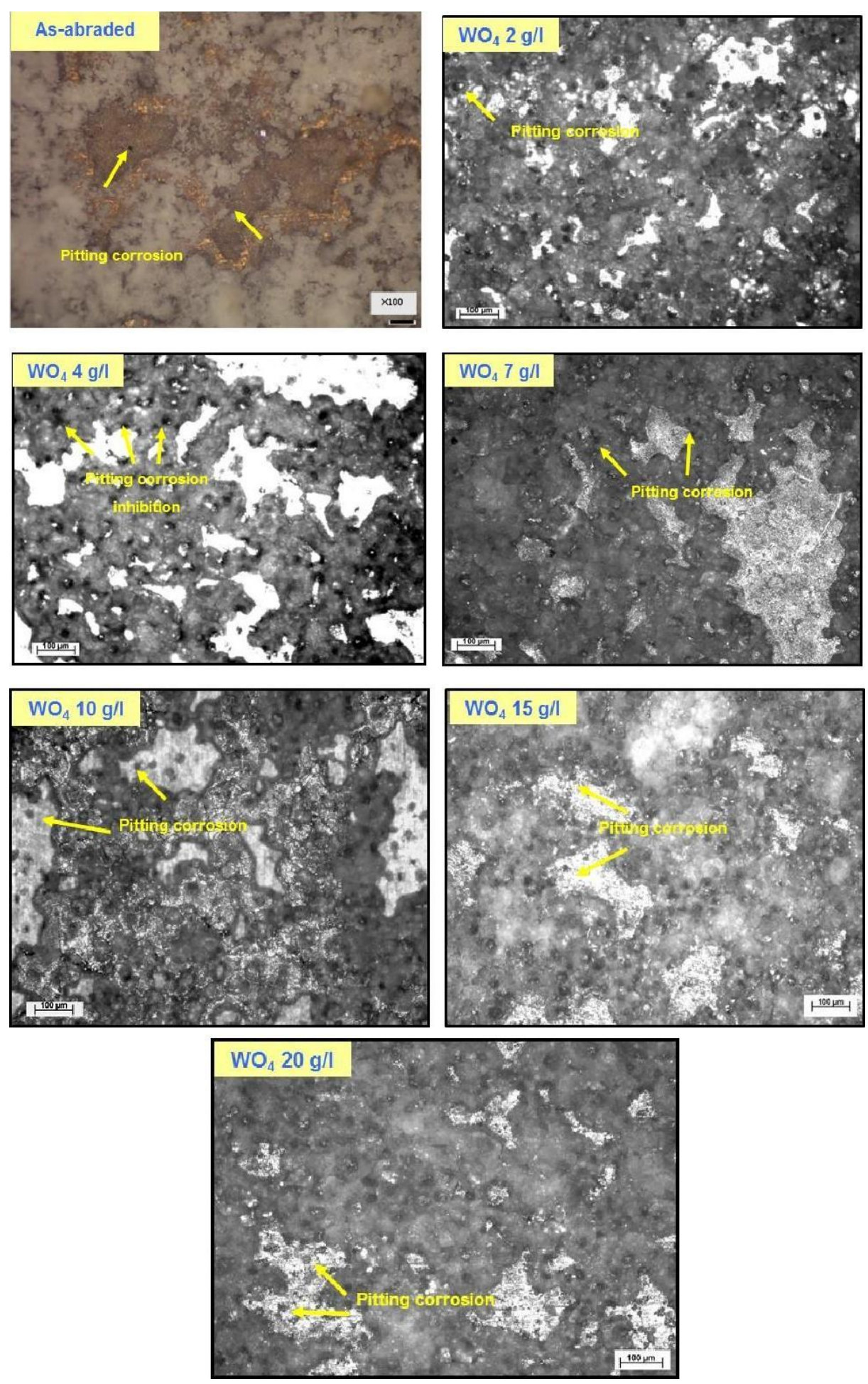

Figure 4:- Microscopic images of the tungstate coated ZE41 magnesium alloy substrates after one week of free immersion in $3.5 \% \mathrm{NaCl}$ solution.

\section{SEM-EDS micrographs:-}

SEM micrograph and EDS microprobe analysis of the uncoated magnesium samples before corrosion in $3.5 \% \mathrm{NaCl}$ solution revealed formation of rare-earth $(\mathrm{Gd}$ and $\mathrm{Nd})(\mathrm{Gd}, \mathrm{Nd}$ and zinc are present as alloying elements in ZE41 substrates). The presence of oxygen indicates the formation of zinc oxide and/or magnesium hydroxide. However, 
the surface distribution of these oxides formed on the Mg substrate is not uniform and hence, some surface defects which

(a)

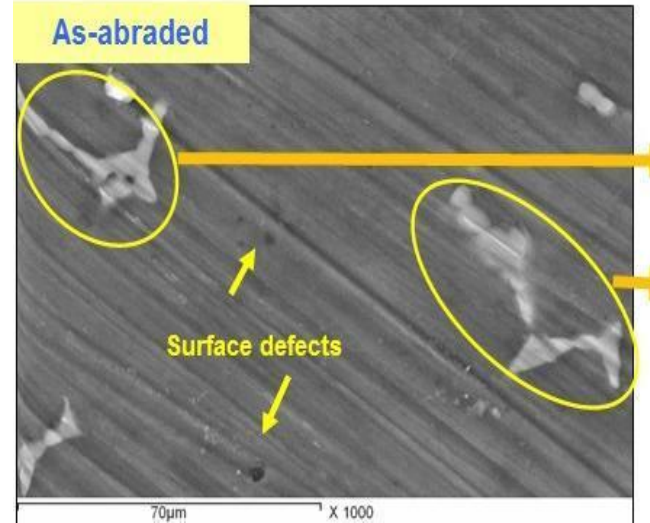

stimulate pitting corrosion on

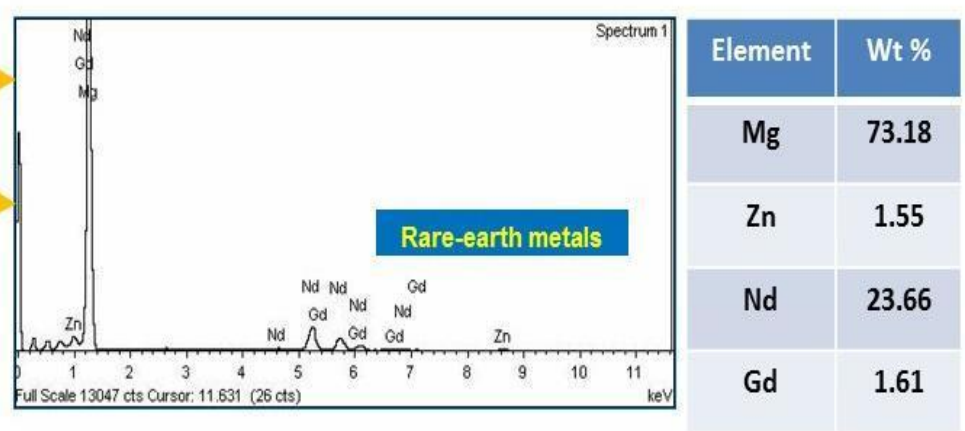

(b)
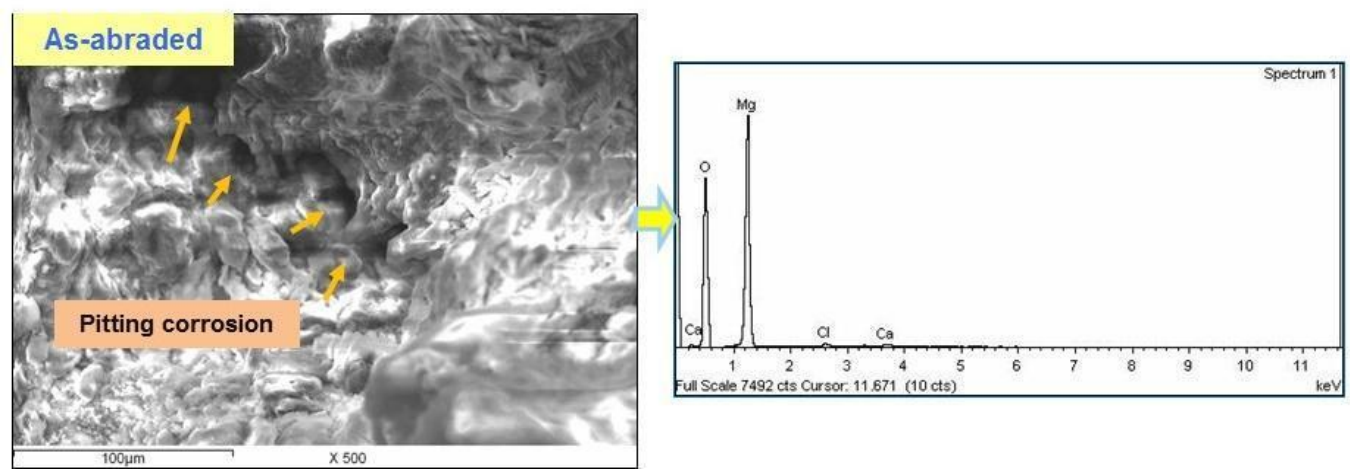

\begin{tabular}{|c|c|}
\hline Element & Wt \% \\
\hline $\mathrm{O}$ & 58.48 \\
\hline $\mathrm{Mg}$ & 40.76 \\
\hline $\mathrm{Cl}$ & 0.46 \\
\hline $\mathrm{Ca}$ & 0.31 \\
\hline
\end{tabular}

Figure 5:- SEM-EDS for the uncoated samples before (a) and after (b) one week of corrosion in $3.5 \% \mathrm{NaCl}$ solution. The images focus into the surface defects and occurrence of localized corrosion after corrosion

ZE41 alloy upon immersion in $\mathrm{NaCl}$ solution were observed [25]. Moreover, the sharp potential difference between the formed rare-earth oxides phases (acts as a cathode) inside the Mg matrix (acts a anode) results in building up micro-electrochemical cells and enhancing galvanic corrosion. Upon immersion in corrosive chloride solution, the galvanic corrosion propagate and enhance intergranular corrosion around the rare-earth phases. At the end, the rareearth phase can debond from the matrix and leaves a hole. In fact, these holes can make a big confusion under the microscopic examination because they appear like pitting corrosion (Fig. 5).

After tungstate treatment, it was expected that a film of W-rich magnesium hydroxide be formed. However, XRD was not able to detect the presence of $\mathrm{W}$, in all cases, which confirms that the film formed is relatively thin and out of the accuracy limits of the X-ray. SEM micro-image showed that the film formed due to $4 \mathrm{~g} / \mathrm{l}$ tungstate treatment is the best among the other concentrations in terms of the coating distribution and surface morphology (Figs 6-8).

(a)
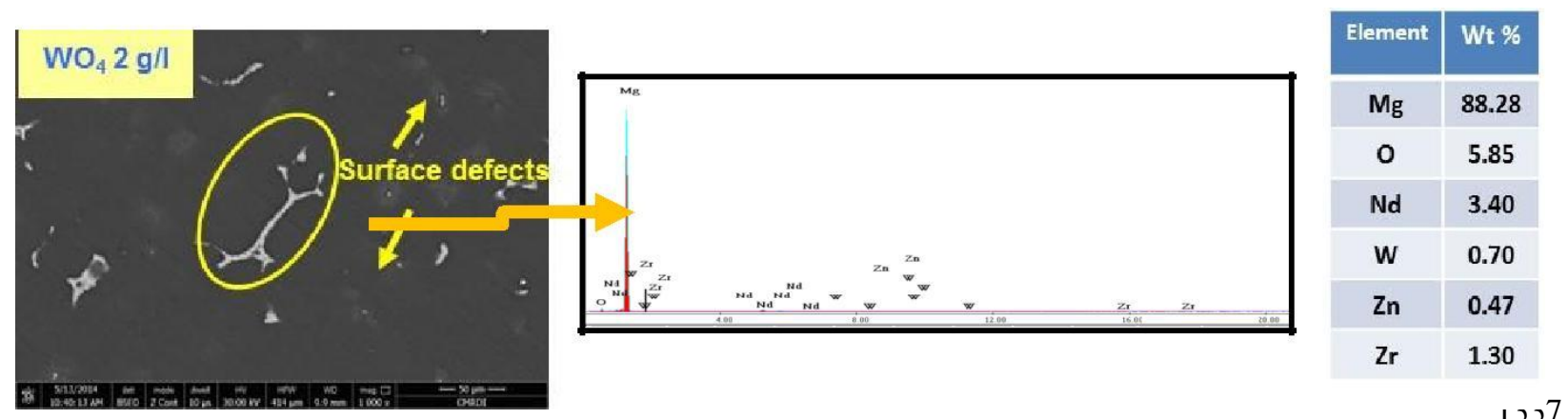

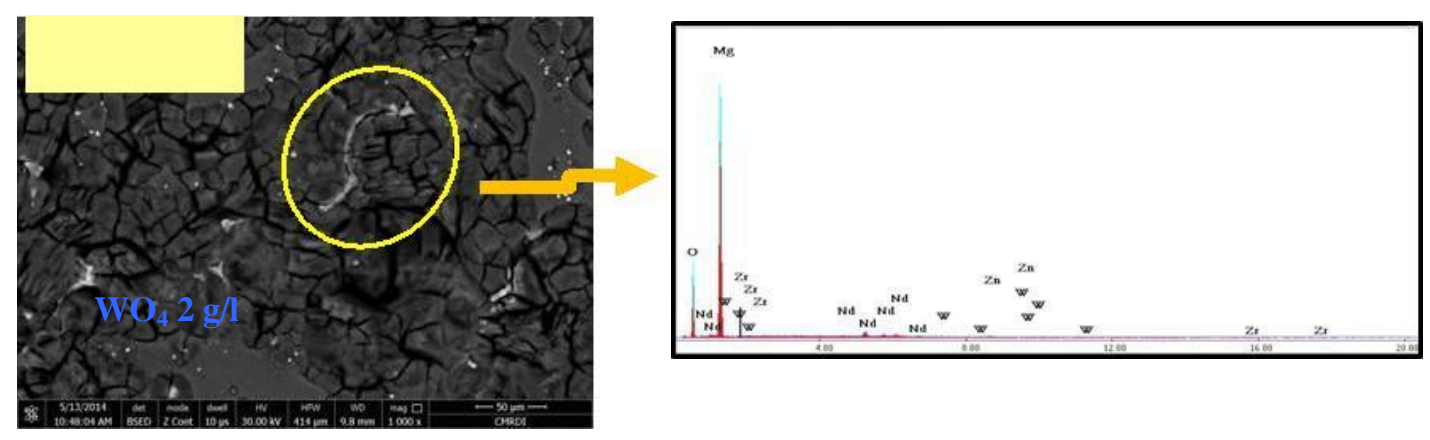

\begin{tabular}{|c|c|}
\hline Element & Wt \% \\
\hline $\mathrm{Mg}$ & 60.35 \\
\hline $\mathrm{O}$ & 32.31 \\
\hline $\mathrm{Nd}$ & 4.66 \\
\hline $\mathrm{W}$ & 0.91 \\
\hline $\mathrm{Zn}$ & 1.08 \\
\hline $\mathrm{Zr}$ & 0.69 \\
\hline
\end{tabular}

(b)

Figure 6:- SEM-EDS for the tungstate coated samples at $2 \mathrm{~g} / \mathrm{l}$ before (a) and after (b) one week of corrosion in 3.5 $\% \mathrm{NaCl}$ solution.
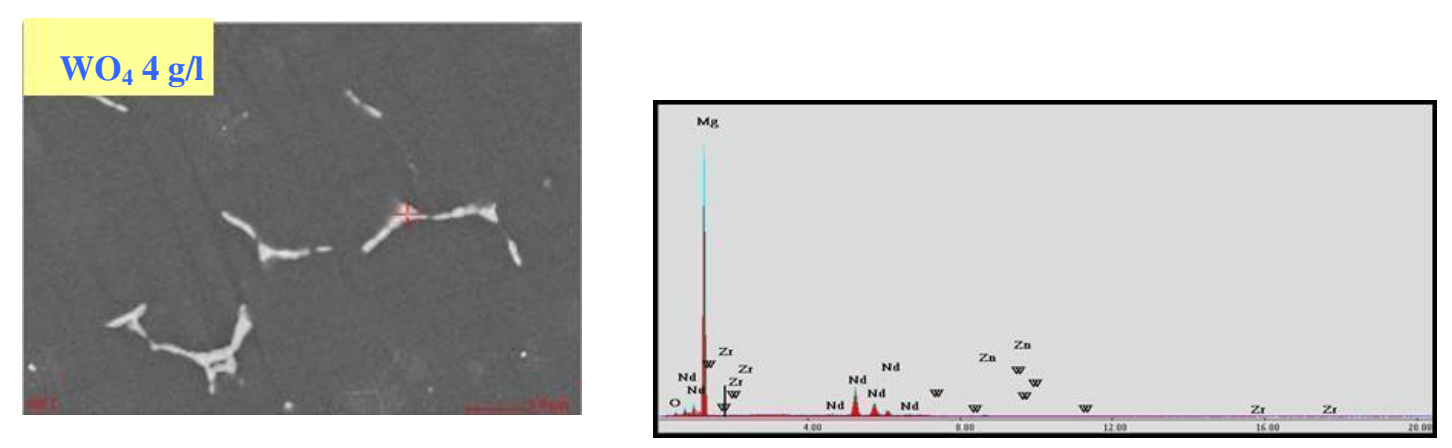

\begin{tabular}{|c|c|}
\hline Element & $W \mathrm{t} \%$ \\
\hline $\mathrm{Mg}$ & 73.85 \\
\hline $\mathrm{O}$ & 2.16 \\
\hline $\mathrm{Nd}$ & 21.23 \\
\hline $\mathrm{W}$ & 0.48 \\
\hline $\mathrm{Zn}$ & 1.14 \\
\hline $\mathrm{Zr}$ & 1.14 \\
\hline
\end{tabular}

(a)
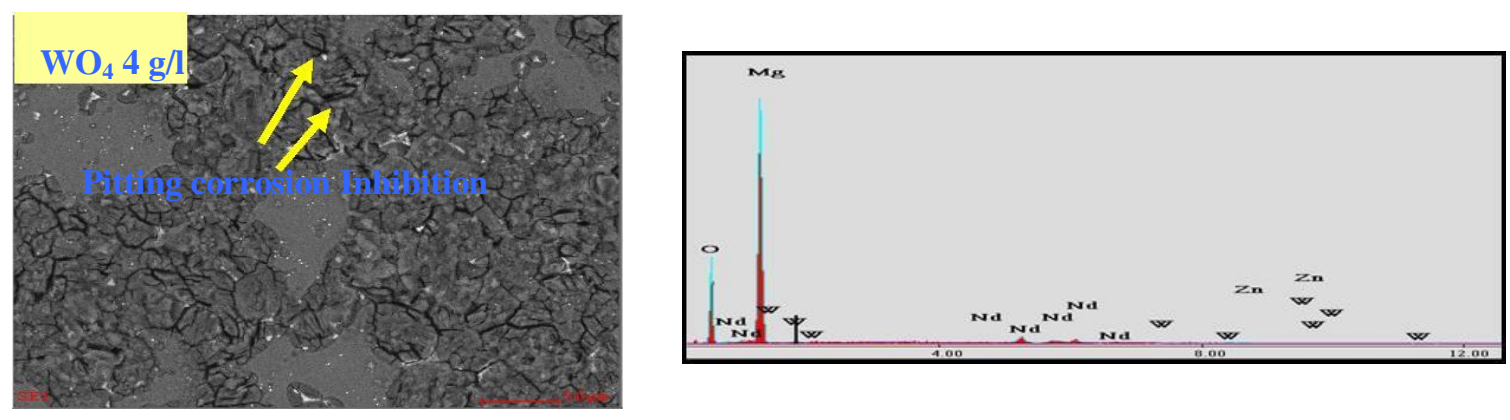

\begin{tabular}{|c|c|}
\hline Element & Wt \% \\
\hline $\mathbf{M g}$ & $\mathbf{5 8 . 9 5}$ \\
\hline $\mathrm{O}$ & 34.91 \\
\hline $\mathrm{Nd}$ & 4.76 \\
\hline $\mathbf{W}$ & 0.75 \\
\hline $\mathrm{Zn}$ & 0.64 \\
\hline
\end{tabular}

(b)

Figure 7:- SEM-EDS for the tungstate coated samples at $4 \mathrm{~g} / \mathrm{l}$ before (a) and after (b) one week of corrosion in 3.5 $\% \mathrm{NaCl}$ solution. 

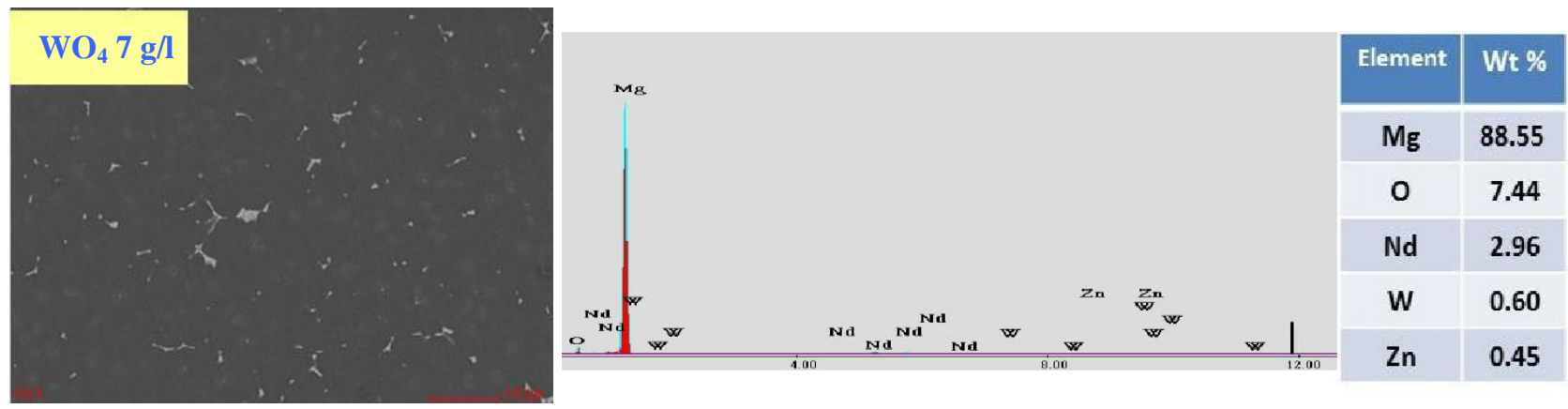

(a)
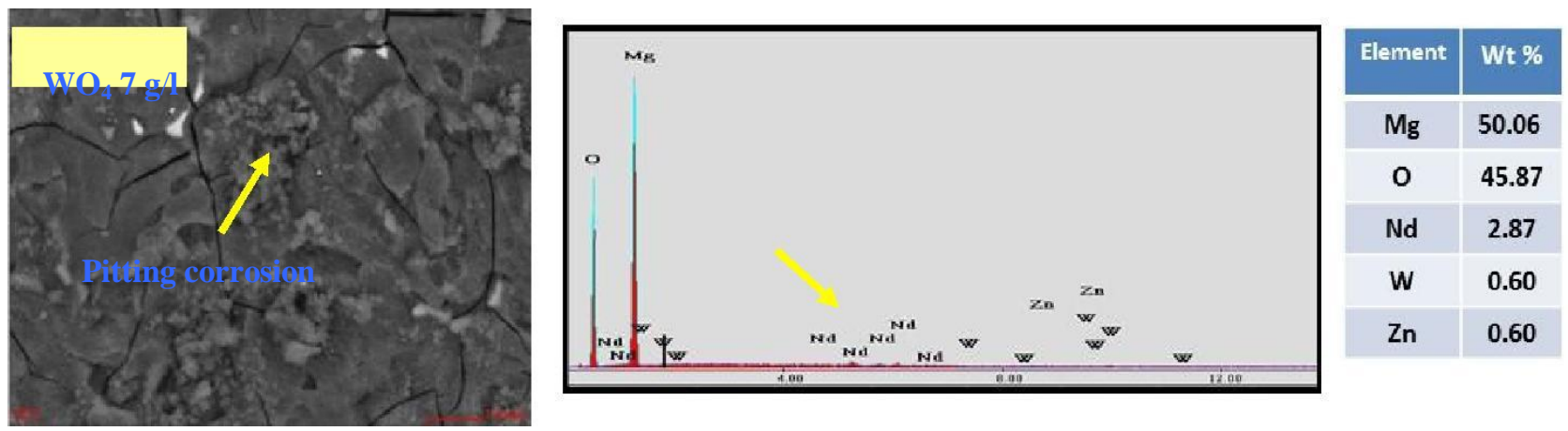

(b)

Figure 7:- SEM and -EDS for the tungstate coated samples at $4 \mathrm{~g} / \mathrm{l}$ before (a) and after (b) one week of corrosion in $3.5 \% \mathrm{NaCl}$ solution.

When the tungstate coated samples were immersed in corrosive $3.5 \% \mathrm{NaCl}$ solution, the samples coated with diluted tungstate (2 and $4 \mathrm{~g} / \mathrm{l}$ ) showed a distinct improvement in the localized corrosion resistance (pitting and crevice) as shown in Figs. 6 and 7. Conversely, the sample coated with $7 \mathrm{~g} / \mathrm{l}$ showed noticeable pitting attack and crevice corrosion (Fig. 8). Based on these findings, treatment of ZE41 substrates with the diluted tungstate solution (2 and 4 $\mathrm{g} / \mathrm{l}$ ) offers better resistance to pitting and crevice corrosion than other tungstate concentrations. However, the sample treated with $2 \mathrm{~g} / \mathrm{l}$ tungstate showed few micro-cracks (Fig. 6). Accordingly, the best surface protection efficiency of ZE41 magnesium alloy can be achieved by a one-step surface treatment in $4 \mathrm{~g} / \mathrm{l}$ tungstate solution (Fig. 6).

\section{X-ray diffractometry (XRD):-}

XRD analyses of the corrosion products formed over the as-abraded and tungstate coated samples are given in Fig. 8. XRD spectra showed that $\mathrm{Mg}$ metal is the most predominant corrosion product formed at $4 \mathrm{~g} / \mathrm{l}$ tungstate solution. Other coated samples at $2 \mathrm{~g} / 1$ or $7 \mathrm{~g} / \mathrm{l}$ tungstate solution revealed formation of magnesium hydroxide $\mathrm{Mg}(\mathrm{OH})_{2}$. 


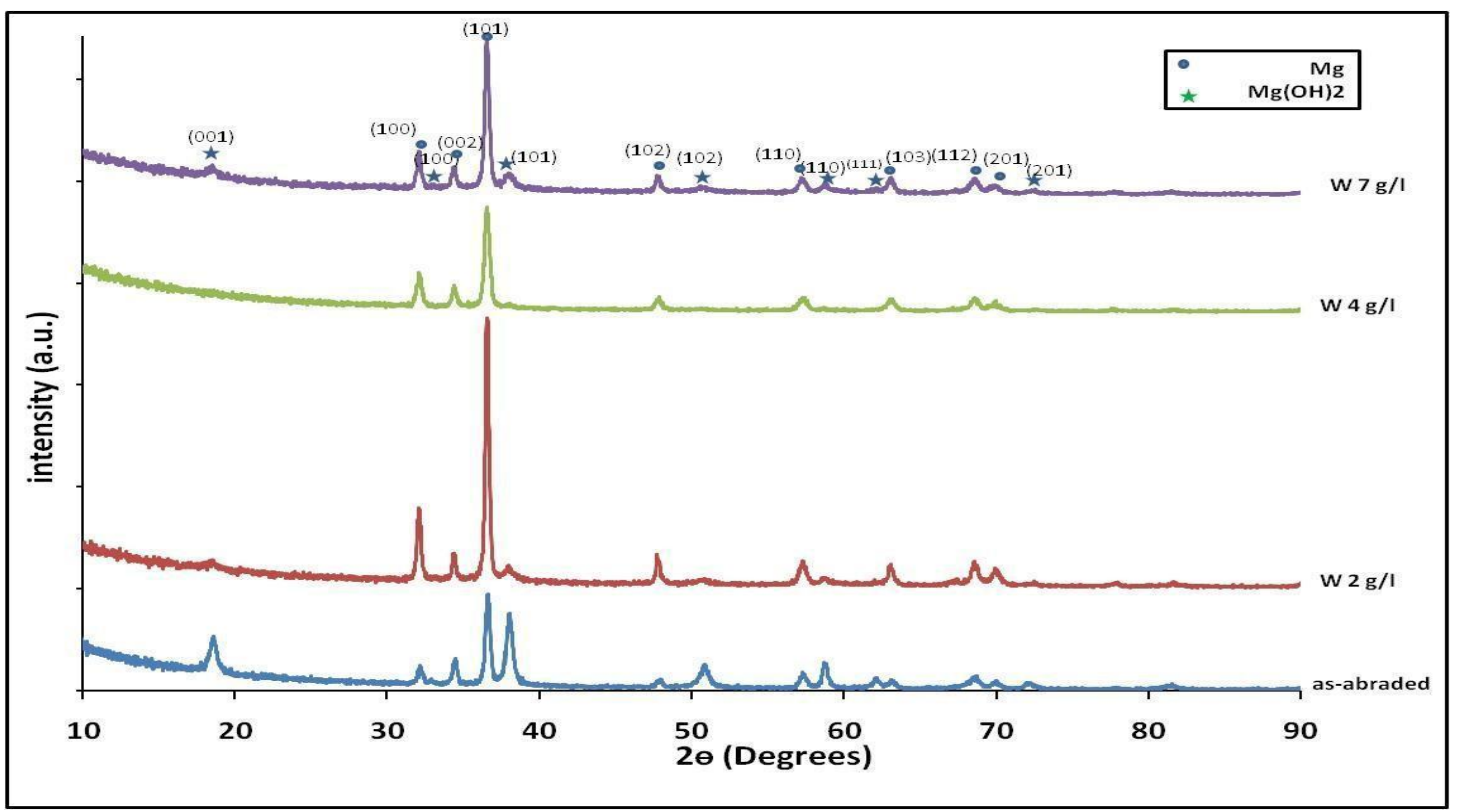

Figure 8:- XRD analysis of the corrosion products formed at tungstate coated samples after immersion in $\mathrm{NaCl}$ solution.

\section{Electrochemical impedance spectroscopy:-}

The surface resistance of the newly developed ZE41 magnesium alloy substrates before and after tungstate treatment at different concentrations ranging from $0-20 \mathrm{~g} / \mathrm{l}$ has been evaluated in $3.5 \% \mathrm{NaCl}$ solution. According to Nyquist plots (Fig 8a), the corrosion resistance of the ZE41 magnesium alloy substrates improved with tungstate surface treatment at low concentration ( 2 and $4 \mathrm{~g} / \mathrm{l})$. Increasing the tungstate concentration more than $4 \mathrm{~g} / \mathrm{l}$ has an adverse effect on the localized corrosion resistance.

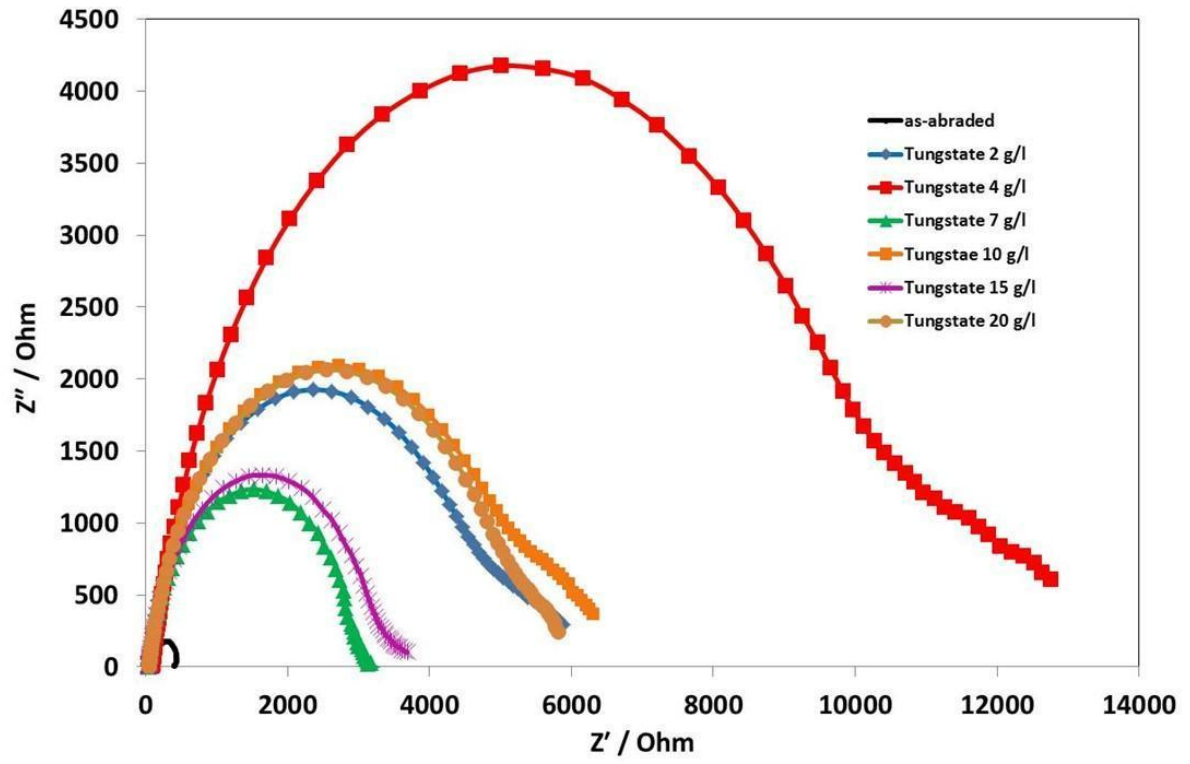

(a) 


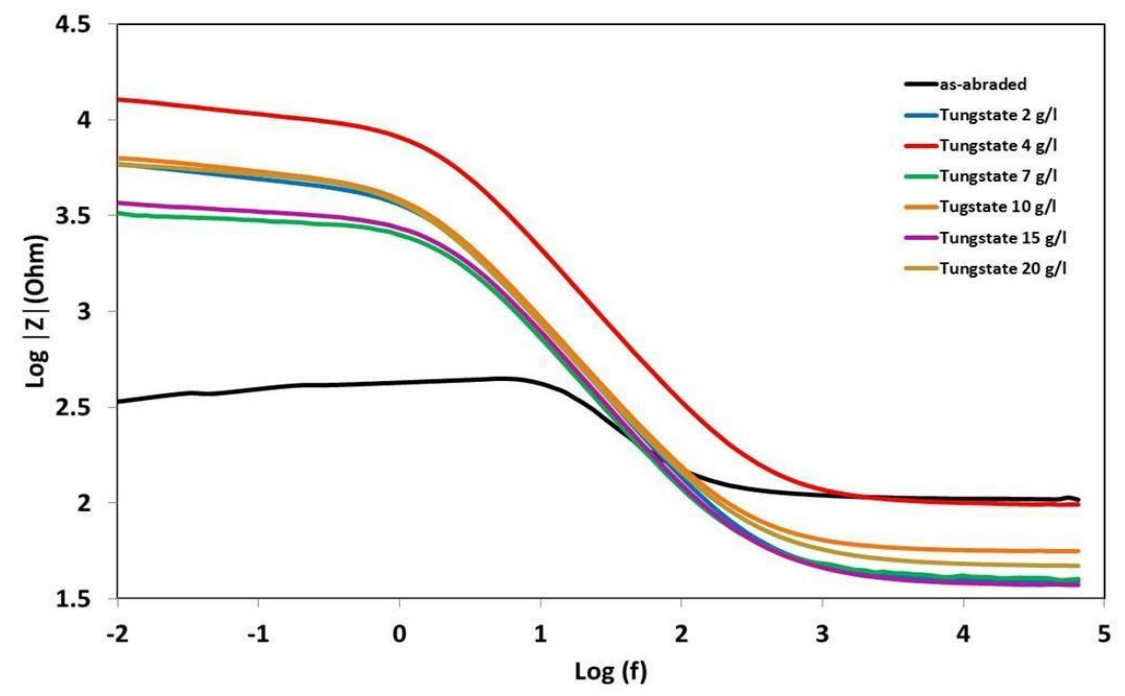

(b)

Figure 9a:- Nyquist plots (a) and Bode (b) plots of the uncoated and tungstate coated magnesium samples after one week of immersion in $3.5 \% \mathrm{NaCl}$ solution

As-abraded samples showed a surface resistance of approximately $0.45 \times 10^{3} \Omega . \mathrm{cm}^{2}$ after one week of immersion in corrosive $3.5 \% \mathrm{NaCl}$ solution. The surface resistance improved almost thirty times for the sample coated with $4 \mathrm{~g} / \mathrm{l}$ tungstate. The surface resistances values were $13.5 \times 10^{3} \Omega . \mathrm{cm}^{2}$ for the sample coated with $4 \mathrm{~g} / \mathrm{l}$ tungstate. Increasing the tungstate concentration proved to have an adverse effect of the surface resistance of ZE41 alloy in chloride containing solution. The surface resistances decreased to be $3.2 \times 10^{3}, 3.8 \times 10^{3}, 5.8 \times 10^{3}, 5.8 \times 10^{3}$ and $6.3 \times 10^{3}$

$\Omega . \mathrm{cm}^{2}$ for the samples coated with 7, 15, 2, 20 and $10 \mathrm{~g} / \mathrm{l}$ tungstate, respectively. Accordingly, the samples coated with $4 \mathrm{~g} / \mathrm{l}$ tungstate showed the best surface protection which confirm the previous results of visual inspection, macro-image, and SEM-EDS.

The resistance spectra in Bode plots (Fig.9b) provide further explanation of these observations where the samples treated in tungstate solution $(4 \mathrm{~g} / \mathrm{l})$ showed the highest polarization resistance $\left(\mathrm{R}_{\mathrm{p}}\right)$ compared with the as-abraded samples and the other coated samples coated with other tungstate solution. The resistance values of the diluted tungstate coated samples reflect good barrier properties, associated with the impediment of the electrolyte to reach the metallic substrate due to the formation of the tungstate-rich magnesium hydro(oxide) film over the substrate.

\section{Cyclic voltammetry:-}

Cyclic voltamograms of the uncoated and tungstate coated samples are shown in Fig. 10. The measured corrosion potentials, $\mathrm{E}_{\text {corr }}$, ranges from -1.4 to $-1.55 \mathrm{~V}$ indicating no pronounced differences, however; coated samples show slightly more noble $\mathrm{E}_{\text {corr }}$ compared to the uncoated sample. The area under the loop which represents the chance of pitting corrosion to occur is smaller in the $4 \mathrm{~g} / \mathrm{l}$ tungstate samples compared with other samples. This is in conformity with previous finding that the $4 \mathrm{~g} / \mathrm{l}$ tungstate sample show the best performance.

The presence of some tiny pits, shown by surface examination, for the 7 and $4 \mathrm{~g} / \mathrm{l}$ tungstate samples can be attributed to formation of very thin tungsten-rich magnesium hydroxide film that could not be detected by XRD and EDS. This film behaves as a barrier to protect the material substrate from the reaction with dissolved oxygen in $\mathrm{NaCl}$ solution and hence impedes the localized corrosion by shifting the cathodic reaction to more noble current and shifting the anodic reaction to more noble potential. However, because this film is very thin, it cannot prevent the general corrosion due to the $\mathrm{Mg}$ ions diffusion. 


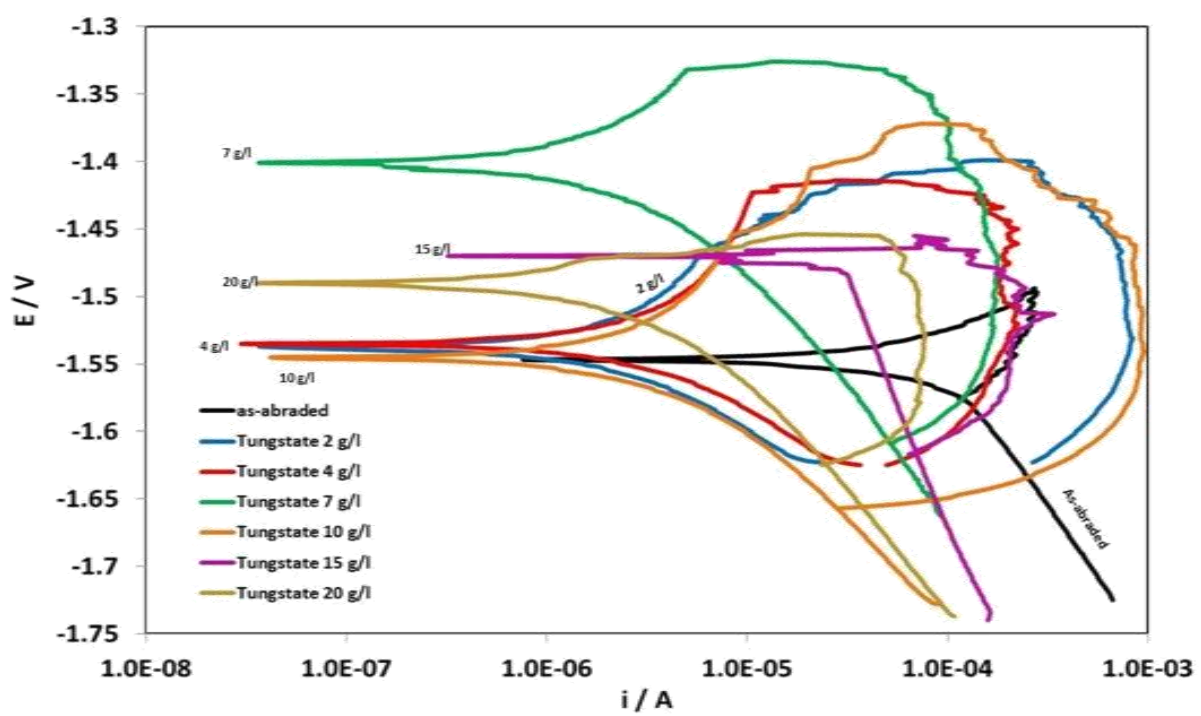

Figure 10:- Cyclic voltammetry curves for uncoated and tungstate coated magnesium samples after one week of immersion in $3.5 \% \mathrm{NaCl}$ solution

The main advantage of the new tungstate surface treatment approach proposed in this paper is the simplicity of the coating process compared with several high performance coatings technology recently investigated in the literatures which imply several coatings steps and several coating layers [9, 17-19]. Another advantage is the safety of tungstate to environment and coatings workers compared with the process involving toxic chromate.

\section{Conclusions:-}

1. This paper discusses a new approach for designing chrome-free coatings based on tungstate surface treatment for improving the corrosion resistance of a newly developed ZE41 magnesium alloy in chloride containing environment.

2. A one-step coating formed by simple free immersion in a diluted tungstate solution for quite short time (10 $\mathrm{min}$ ) was found promising to increase the corrosion protection of newly developed ZE41 magnesium alloy substrates.

3. According to the surface examination, electrochemical impedance spectra and cyclic voltammetry measurements, $4 \mathrm{~g} / \mathrm{l}$ tungstate is the optimum tungstate concentration that gives the highest performance coating which offfer the best corrosion protection to the $\mathrm{Mg}$ substrate in $\mathrm{NaCl}$ solution.

4. It was proven that tungstate coating improves the corrosion inhibition characteristics of the newly developed ZE41 magnesium alloy substrates by formation a manganese-rich oxide film over the pitting areas.

5. It is worthy to mention that the tungstate coatings proposed in this study would be only a first pre-treatment (primer) film to the newly developed ZE41 magnesium alloy substrates, and a final top coat will be crucial to reach an adequate corrosion protection.

\section{Acknowledgements:-}

The authors would like to thank Prof. Dr. Ahmed Ismail and Prof. Dr. Ibrahim Mohamed Ghayad, CMRDI, Egypt, for their guidance in the optical microscopic examination and corrosion investigation.

\section{References:-}

1. M. K. Kulekci, "Magnesium and its alloys applications in automotive industry", The International Journal of Advanced Manufacturing Technology, 2008, Vol. 39, 9-10, PP 851-865.

2. http://www.magnesium-elektron.com/data/downloads/452A.pdf

3. M.Sabouri, T. Shahrabi, H. R. Faridi and M. G. Hosseini, "Poly Pyrrole and poly pyrrole-tungstate electropolymerization coating on carbon steel and evaluating their corrosion protection performance via electrochemical impedance spectroscopy",Progress in organic coating 64 (2009) 429 - 434.

4. Ding Jun, Liang Jun, Hu Li-tian, HAO Jing-cheng and XUE Qun-ji, "Effects of sodium tungstate on characteristics of microarc oxidation coatings formed on magnesium alloy in silicate-KOH electrolyte", Trans. Nonferrous Met. Soc. China 17 (2007) 244-249. 
5. Chun-Chieh Tseng, Jeou-Long Lee, Tzu-Hsuan Kuo,Shie-Nan Kuo and Kuo-Hui Tseng, " The Influence of sodium tungstase concentrationand anodizing conditionon microarc oidation (MAO) coating for aluminum alloy", Surface \&Coating Technology 206 (2012) 3437-3443.

6. K.Kamaraj, V. Karpakam, S. Sathiyanarayanan, S. Syed Azim and G. Venkatachari, "Synthesis of tungstate doped polyaniline and its usefulness in corrosion protective coatings", Electrochimica Acta 56 (2011) 92629268.

7. Xin Shu, Yuxin Wang, Xin Lu, Chuming Liu and Wei Gao, "Parameter optimization for electroless Ni- W - P coating", Surface \& Coating Thchnology 276 (2015) 195 - 201.

8. H. Ardeean, I. Frateur and P. Marcus, "Corrosion protection of magnesium alloys by cerium, zirconium and niobium-based conversion coatings", corrosion Science,Vol. 50, No. 7, 2008, PP. 1907-1918.

9. H. Ardelean, I. Frateur, S. Zanna, A. Atrens and P. Marcus, "Corrosion protection of AZ91 magnesium alloy by anodizing in niobium and zirconium-containing electrolytes", Corrosion Science, Vol. 51, No. 12, 2009, PP 3030-3038.

10. K. Z. Chong and T. S. Shih, "Conversion-coating treatment for magnesium alloys by a permenganatephosphate solution”, Materials Chemistry and Physics, Vol. 80, No. 1, 2003, PP 191-200.

11. D. Y. Hwang, Y. M. Kim, D-Y Park, B. Y. Yoo and D. H. Shin, "Corrosion resistance of oxide layers formed on AZ91 Mg alloy in KMnO4 electrolyte by plasma electrolytic oxidation", Electrochimica Acta, Volume 54, Issue 23, 30 September 2009, Pages 5479-5485.

12. D. Y. Hwang, K-R. Shin, B. Yoo, D-H. Lee, D-Y. Park and D-H. Shin, "Characterization of plasma electrolytic oxide formed on AZ91 Mg alloy in KMnO4 electrolyte", Trans. Nonferrous Met. Soc. China 19 (2009) pages 829-834.

13. A.S. Hamdy (Editor): "High Performance Coatings for Automotive and Aerospace Industries", Nova Science Publishers, NY, USA, ISBN: 978-1-60876-579-9, 2010.

14. A.S. Hamdy and I. Tiginyanu (Editors), "Nanocoatings and Ultra Thin-Films", Woodhead Publishing Limited, UK, ISBN: 978-1-84569-812-6, 2011.

15. A.S. Hamdy (Editor): "Handbook of Smart Coatings for Corrosion Protection", Woodhead Publishing Limited, UK, to be ready April 2013.

16. A. S. Hamdy, "Enhancing corrosion resistance of magnesium alloy AZ91D in 3.5\% NaCl solution by cerate conversion coatings", J. Anti-Corrosion Methods and Materials, Vol. 53, No. 6 (2006) 367-373.

17. A.S. Hamdy and D.P. Butt, "Novel anti-corrosion nano-sized vanadia-based thin films prepared by sol-gel method for aluminum alloys", J. Materials Processing Tech., Vol. 181, No. 1-3, PP.76-80, 2007.

18. A.S. Hamdy, "Alkaline based surface modification prior to ceramic based cerate conversion coatings for magnesium AZ91D”, J. Electrochemical and Solid-State Letters, Vol.10, No.3, C21-C25, 2007.

19. A.S. Hamdy, "A novel approach in designing chrome-free chemical conversion coatings for automotive and aerospace materials", European Coatings Journal, Vol. 86, No. 3, PP 43-50, 2008.

20. A. S. Hamdy, "Effect of surface modification and stannate concentration on the corrosion protection performance of magnesium alloys", J. Surface Coatings and Technology, 203 (2008), pp. 240-249.

21. A.S. Hamdy, "Novel approaches in designing high performance nano and nano-composite coatings for industrial applications", Int. J. Nanomanufacturing, Vol. 4, Nos. 1/2/3/4, PP. 235-241, 2009.

22. A.S. Hamdy, and M. Farahat, "Chrome-free zirconia-based protective coatings for magnesium alloys", J. Surface and Coatings Technology, 204 (2010) 2834-2840.

23. A.S. Hamdy, I. Doench, and H. Möhwald, "Assessment of a one-step intelligent self-healing vanadia protective coatings for magnesium alloys in corrosive media", J. Electrochimica Acta, 56 (2011) 2493.

24. A.S. Hamdy, I. Doench, and H. Möhwald, "Smart self-healing anti-corrosion vanadia coating for magnesium alloys", Progress in Organic Coatings, 72 (2011) 387-393.

25. A.S. Hamdy, "Casting out chromium: Non-toxic pre-treatments protect magnesium and aluminium alloys", European Coatings Journal, No. 3 (2012), pp. 16-20.

26. A.S. Hamdy, I. Doench, and H. Möhwald, "Smart vanadia-based coatings of self-repairing functionality for advanced magnesium Elektron ZE41 Mg-Zn-rare earth alloy", Surface Coatings \& Tech., 206, 2012, 36863692.

27. A.S. Hamdy, I. Doench, and H. Möhwald, "The effect of vanadia surface treatment on the corrosion inhibition characteristics of advanced magnesium Elektron 21 alloy in chloride media", Int. J. Electrochemical Science, 7, 2012, PP. 7751-7761.

28. A.S. Hamdy and D. Butt, "Novel smart stannate based coatings of self-healing functionality for magnesium alloys",J. Electrochimica Acta, in review. 